\title{
Expanding
}

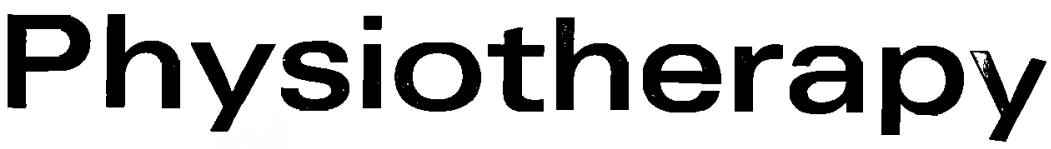

Author: Katherine A. Glauber, B.Sc. (Physiotherapy) (Witwatersrand).

Hospital: Physiotherapist, Germiston Hospital. This article was taken from the undergraduate thesis completed in 1975 , entitled "Physiotherapy in the Community".

\section{Comprehensive Health Care}

The concept of "wholeness" is incorporated into the World Health Organisation's definition of health. It states that health is a condition of complete physical, mental and social well-being, and not merely one where disease or infirmity is absent. The health of an individual may be seen as being on a relative scale between well and ill.
The areas of medicine which contribute to the concep of Comprehensive Health Care are those of preventive, clinical and rehabilitative medicine.

The profession of Physiotheraphy has always concerned itself with the above three facets of health care; but in practice the main emphasis has been on clinical and rehabilitative physiotherapy.

\section{FIGURE I: ROGERS HEALTH STATUS SCALE}

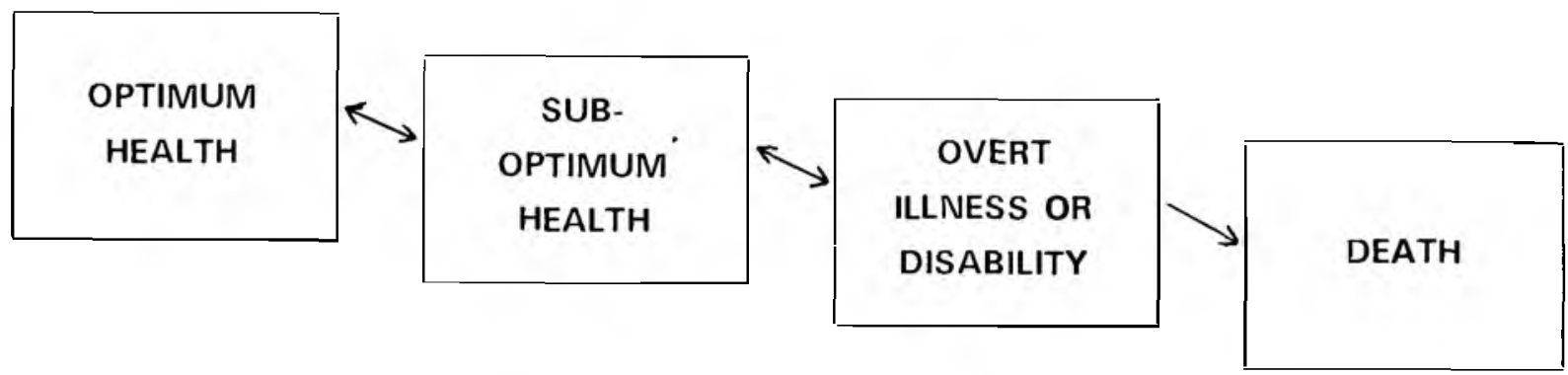

\section{Community Health}

A Community may be defined as a population of differing size, not necessarily held together by geographical boundaries. The common factor may be an intellectual interest (as in a university town) or the community may be the inmates of a mental institution. The concept of Health is part of a community's culture. The health of a community is the summation of the health of its individual members. Community Medicine may be defined as that group of skills which can be applied to a community to improve its health. Epidemiology is the methed used to study the health of populations, be they those of a hospital, town, or country. Epidemiology seeks to establish the patterns of disease in a community and the causal factors of these diseases. This involves Health Care Research, which is a vast field ranging from the analysis of morbidity and mortality rates to the ccst-benefit analvsis of different types of hospital organisation and administration.

\section{The Epidemiological Approach:}

Table I

The example of Rheumatoid Arthritis will be used to demonstrate this approach.

\section{Stages of the Epidemiological Approach to a Problem}

Figure II

\section{Natural History of Rheumatoid Arthritis}

I-IV are intervention options. As may be seen, early intervention is preferable but may not always be practical, in terms of size of population, costly chemical analyses etc.

Physiotherapy is mainly involved in stages III-V in the above example, but may be involved in stage II in a consultant and counselling role e.g. advising on what early signs may present. At the present time, rheumatoid arthritis cannot be entirely prevented but the $2^{\circ}$ sequelae e:g. severe deformities may be prevented. The physiotherapist's role in rheumatoid arthritis in concerned with the articular aspects os the disease, but it must not be forgotten that there are systemic manifestations e.g. with eyes and heart.

In considering community physiotherapy, the role of the physiotherapist must come under review. The traditional role of the physiotherapist has been mainly that of "treater"; the time has come for this role to be expanded, especially in the fields of education and research. 
TABLE I

STAGES OF THE EPIDEMIOLOGICAL APPROACH TO A PROBLEM

\section{DEFINITION OF THE PROBLEM}

EG. DETERMINE EFFECTIVENESS OF CURRENT MANAGEMENT OF RHEUMATOID ARTHRITIS

\section{LOOK FOR CAUSES}

EG. GENETIC, BIOCHEMICAL, ENVIRONMENTAL

\section{CONSIDER INTERVENTION OPTIONS}

LOOK FOR HIGH-RISK GROUPS

SURGICAL vS. MEDICAL REGIME

EG. EARLY DETECTION AND PREVENTION

\section{EVALUATE WHICH INTERVENTION OPTION WORKS BEST}

DECREASED COST OF SURGICAL INTERVENTION

DECREASED SEVERITY OF DEFORMITIES

EG. INCREASED LIFE EXPECTANCY

\section{IMPLEMENTATION}

IE. IMPLEMENTING THE MOST EFFECTIVE INTERVENTION OPTION

EVALUATION OF THE WHOLE PROGRAMME

THIS WORKS ON A CONTINUAL FEED-BACK SYSTEM SO THAT MODIFICATIONS OF THE PROGRAMME CAN BE MADE IF NECESSARY

FIGURE II: NATURAL HISTORY OF RHEUMATOID ARTHRITIS

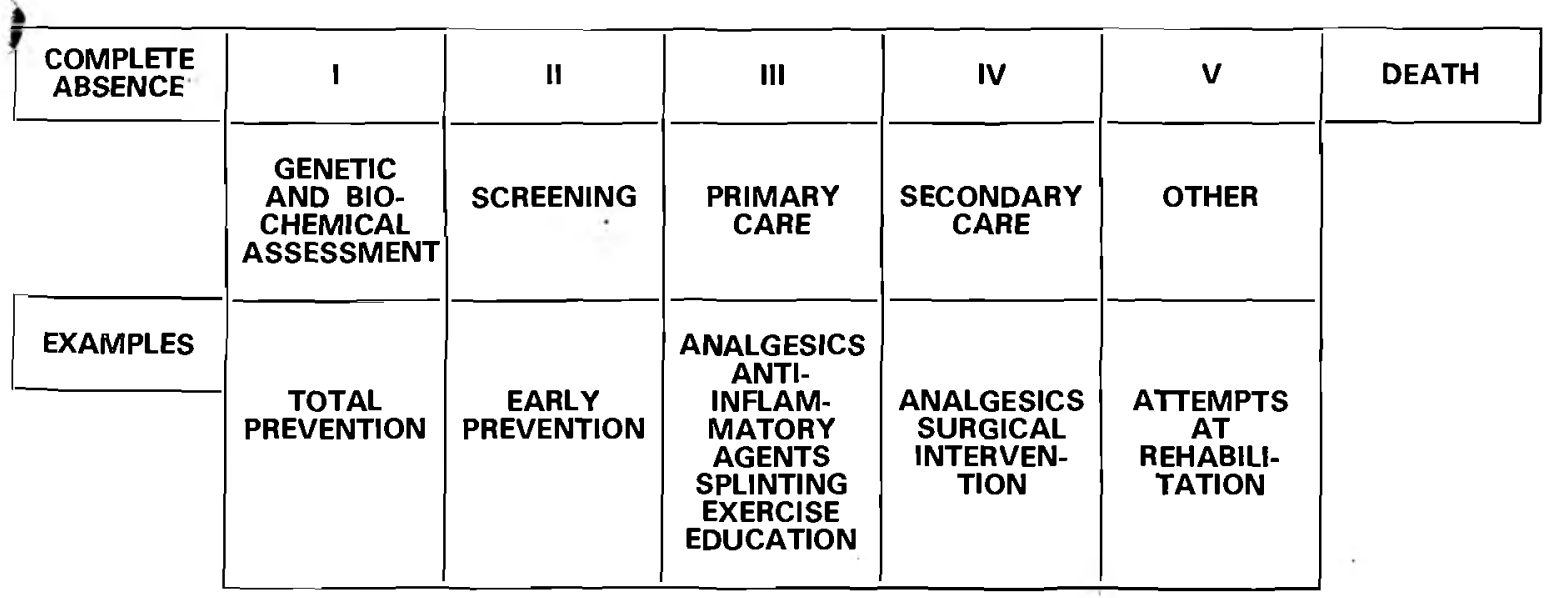


TABLE ॥

\section{THE EXTENDED ROLE OF THE PHYSIOTHERAPIST}

\begin{tabular}{|c|c|c|}
\hline FUNCTION & eg. INDIVIDUAL & eg. COMMUNITY \\
\hline ASSESSING & $\begin{array}{l}\text { ESTABLISH POTENTIAL OF PATIENT; } \\
\text { DECIDE ON AIMS OF TREATMENT }\end{array}$ & $\begin{array}{l}\text { ESTABLISH WHETHER DOMICILIARY SER } \\
\text { VICE WILL BENEFIT A PARTICULAR } \\
\text { COMMUNITY }\end{array}$ \\
\hline EVALUATING & $\begin{array}{l}\text { CONTINUAL MONITORING OF PATIENT'S } \\
\text { PROGRESS }\end{array}$ & $\begin{array}{l}\text { COST-BENEFIT ANALYSIS OF DOMICI. } \\
\text { LIARY PHYSIOTHERAPY SERVICE }\end{array}$ \\
\hline COUNSELLING & $\begin{array}{l}\text { ADVISING PARENTS OF HANDICAPPED } \\
\text { CHILD }\end{array}$ & . \\
\hline SUPERVISING & $\begin{array}{l}\text { SUPERVISION OF PATIENT'S PROGRESS } \\
\text { AND OF THE WORK OF AIDES }\end{array}$ & $\begin{array}{l}\text { AS CO-ORDINATOR OF REHABILITATION } \\
\text { TEAM }\end{array}$ \\
\hline $\begin{array}{l}\text { TREATING } \\
\text { PLANNING }\end{array}$ & $\begin{array}{l}\text { PRACTICAL APPLICATION OF CHOSEN } \\
\text { TECHNIQUES }\end{array}$ & \\
\hline PROGRAMME & $\begin{array}{l}\text { TO DECIDE MOST EFFECTIVE MEANS OF } \\
\text { FULFILLING AIMS OF TREATMENT }\end{array}$ & $\begin{array}{l}\text { MAY INCLUDE PILOT STUDY TO ESTAB } \\
\text { LISH WHICH SECTOR OF POPULATION } \\
\text { WILL BENEFIT MOST FROM COMMUNITY } \\
\text { SERVICE }\end{array}$ \\
\hline TEACHING & $\begin{array}{l}\text { INVOLVE THE RELATIVES, NURSES AIDES } \\
\text { AND THE PATIENT HIMSELF IN HIS } \\
\text { REHABILITATION PROGRAMME } \\
\end{array}$ & $\begin{array}{l}\text { HELP EDUCATE TOWARDS TEAM CON. } \\
\text { CEPT }\end{array}$ \\
\hline RECOMMENDING & $\begin{array}{l}\text { ADVISING DOCTOR WHEN PATIENT HAS } \\
\text { RECEIVED MAXIMUM } \\
\text { TREATMENT } \\
\end{array}$ & $\begin{array}{l}\text { AS CONSULTANT } \text { TO GOVERNMENT } \\
\text { HEALTH PLANNING COMMISSIONS (FOR } \\
\text { THE FUTURE!) }\end{array}$ \\
\hline DOCUMENTING & $\begin{array}{l}\text { ACCURATE MONITORING AND RECORD- } \\
\text { ING OF PATIENT'S PROGRESS }\end{array}$ & $\begin{array}{l}\text { TO GATHER EPIDEMIOLOGICAL DATA FOR } \\
\text { HEALTH CARE RESEARCH }\end{array}$ \\
\hline
\end{tabular}

\section{Table II}

\section{The Extended Role of the Physiotherapist}

The type of work done-by the community physiotherapist would be very different to that found in the usual hospital environment. The new role requires an outward looking, socially-minded person who dces not recognise rigid boundaries between herself, the occupational therapist and the nursing staff. She must be prepared to ask for, and give help when it is needed. The ability to adapt and use initiative in whatever situation she finds herself would be most useful, In addition the new physiotherapist will have to learn the skills of management and administration.

The most important method by means of which physiotherapy knowledge can be spread out in to the community is by breaking down the barriers of the traditicnal physiotherapist - patient relationship. This involves teaching parents, friends, voluntary workers and the patients themselves how to perform routine tasks in the management of certain patients, for example, the rehabilitation of stroke cases in the home. Bauer says: "The essential element of the therapeutic process is not what a physiotherapist does for a patient, but rather what the patient is taught and motivated to do for himself". This idea places the physiotherapist in the role of the skilled educator disseminating knowledge. Not only must the physiotherapist teach these skills, but she must continually reassess the program and supervise the helpers whom she has trained. It is her responsibility to see that these helpers are never left in the position of not knowing how to cope.

We now see the physiotherapist acting as manager of a team consisting of those people to whom she is delegating work. Effective delegation of work involves managerial skills which will in many cases be new to the physiotherapist, and quite different from the traditicnal limited role. Initially the physiotherapist may baulk at the idea of giving up routine work which she has been doing for many years; and she will possibly fear that the helpers may become more expert at a certain task than she herself. However, I feel that the challenge of the enlarged role of the physiotherapist should offset these problems. The effects of delegation may not be immediately apparent, but when they do appear the ultimate level of efficiency will be far higher than when the physiotherapist does all the work by herself.

If the advantages of spreading knowledge into the community are appreciated, it becomes apparent that our first task is to educate physiotherapists to an awareness of their wider role. The skills which a physiotherapist has took much time and money to accumulate; if she merely uses these skills to treat patients then she is not exploiting her full potential for the wider benefit of the community. Too often it is said that physiotherapists do not "push" themselves enough. The following opinions illustrate this pcint: "We haven't got time to do anything else but treat the patient"; "The patient appreciates our services and that is all that matters"; "We cannot participate in research because we are not trained in the methods". These statements indicate that the greatest obstacle to initiating, quality care, continuous learning, or some form of research, is individual acceptance of the status quo and complacency about traditional methods.

This self-effacing attitude must be changed so that the physictherapist can develop a more positive selfimage, which will enable her to begin to educate others. A simple example is provided by the physiotherapist on a ward round waiting in the background for the doctor to delegate patients to her. She should be in the fore- 
front telling the doctor which patients she thinks she help. In this way the doctor learns where physiotherapy can be of benefit. He also acquires a new thespect for the physiotherapist because she is taking some of the responsibility for patient care off his shoulders. Once the doctors and nursing staff are more ware of the physiotherapist's role, physiotherapists will assured of their suppart in a public education promme. An example of a physiotherapy public relations programme is to be found in Manitoba, Canada (1974). This nrogramme was mostly media-based and it aimed at improving general public knowledge of physiotherapy. A professional public relations consultant was employed A profess physiotherapists improve their public image. to hision interviews, an open 'hot-line' radio show, letters to the newspapers and a series of lecture-demonthe methods used to stration the public's attention to Physiotherapy. The prodramme has already achieved a greater public awareness. The author feels that the greatest benefit so far has Then on the physiotherapists themselves - they have feater confidence now that they have a public presence nd identity.

The change that is called for must come from within the profession itself. It can begin with the teachers and the profisors in our physiotherapy schools and teaching departments. Our profession will only become more respected when we ourselves have more confidence in the value of what we are teaching and practising.

\section{The Team Approach in Comprehensive Health Care}

For health care to have the maximum benefit for the patient and community, it is necessary that we regard the patient as a complete individual. In assessing and treating a patient, we as physiotherapists must take into account not only his physical conditicn, but his social, emotional and vocational capacities as well. The physiotherapist is not trained to cope with all these aspects and it becomes apparent that a team approach is necessary if the patient is to be understood as a whole. The members of the health care team include doct $c$ rs, nurses, social workers, occupational and physiotherapists and others. There needs to be a great deal of co-operation and co-ordination between team members if the patient is to benefit. The first step towards this co-operation is to show the other members of the team what our aims are, and how we achieve them. Conversely, we have to appreciate the aims of the other members, otherwise there is little value in having the team. It is vital at there be a team co-ordinator who is able to direct the activities of the team in a purposeful manner. This person is most often the general practitioner or the social worker, but it may be the physiotherapist in certain circumstances. The team co-ordinator has a responsibility to keep the other members fully aware of the progress of treatment - this can be done by means of frequent case report-backs.

\section{Analysis of Health Needs in South Africa}

In developed communities it makes good sense to cut down the number of small hospitals and to build big well-equipped and well-staffed hospitals in large centres. This is made possible because of gcod transport and modern communications and a relatively high standard of living in the developed communities. In the developing countries, however, the exact opposite is required, viz. the decentralisation of health services to small clinics in the community. Poor transport, inaccessibility and general poverty in these communities necessitates that health education and health services must be taken into the community to improve the general level of health lt is also vital that secondary workers be trained to take over some of the tasks that highly trained staff waste valuable time doing.
In South Africa we find these two situations existing side by side, with most of the physiotherapy services being cancentrated in the developed sector of the community in large hospitals and in private practices. The example of the Day Hospital Organisation in the Cape Peninsula demonstrates that there is a great need for physiotheraphy in the developing sections of our country; this need is now being fulfilled most successfully. Our problem when considering the last underprivileged sections of our community is one of how to provide adequate service most efficiently. One of the most important answers lies in the training of semi-skilled personnel to carry out routine treatments and to help with the spreading of knowledge of physiotherapy techniques as described above. The role of the physiotherapist here is one of educator, supervisor and manager. It is a very responsible role and one which demands extended use of the physiotherapists abilities. To my mind it is very challenging and equals the thrill of seeing results by means of purely physical techniques. The physiotherapist must take responsibility for the well-being and progress of the patient as well as ensuring that the aides are welltrained and confident in the skills that they have to perform.

As part of a project undertaken in my final year of study, a survey was made of the possibility of establishing a hospital-based domiciliary physiotherapy service in this city. It was felt that due to the lack of adequate rehabilitative services, there was a need for more active physiotherapy in the community. A programme staffed by the married non-practising physiotherapists of this city was envisaged. A favourable response to a questionnaire on this subject was received; many of the physiotherapists felt that they would like to return to work on a part-time basis. They found the idea of acting as educators and advisors to patients in their own homes to be particularly appealing. It was felt that this service could not be established on a voluntary basis, as these physiotherapists are fully qualified health personnel, and as such deserve remuneration for services.

The aims of domiciliary physiotherapy service include provision of physiotherapy to the housebound hospital patient who is unable to afford ambulance fees, or whose health does not permit travel; provision of an economically more advantage us health service than prolonged in-patient care; earlier discharge from hospital if doctors know that the patient will receive follow-up physiotherapy after operation or major illness; lastly the maximum utilisation of the resources of our labour force, by re-employing non-practising physiotherapists.

A role for the physiotherapist as therapist, advisor and consultant can be found in the management of patients of all ages. In the care of pre-school children, particularly the minimally brain damaged child, the physiotherapist can give guidance to parents in the handling of their children in the home environment. While in the home the physiotherapist can note if there are any minor architectural adjustments that could be made to facilitate the child's progress. Any special equipment could then be ordered to the exact specifications of the physiotherapist. The physiotherapist can teach the mother a basic exercise programme and also give her advice on suitable play materials and games f. $r$ the child.

In the care of schoolchildren the physiotherapists could visit the school and explain the child's physical limitations to the teacher and headmaster. In this way the interest of the school would be aroused and would aid in the good overall adjustment of the child. The physiotherapist could also suggest group activities aimed specifically at the handicapped child. A once-weekly visit to the home or school by the physiotherapist could prevent days away from school by having to attend the hospital for treatment. Many children who are in homes and institutions might be able to cope at a normal 
school, if the correct supportive therapy and advice were available. This would lighten the load on these institutions where the waiting lists for admission are always long. The physiotherapist can also act in a preventive capacity in this age group for example in the management of fibro-cystic disease and in screening for the postural defects of scoliosis in adolescents.

The field of geriatrics is wide open to community care, including physiotherapy. A further aim of the above proposed domiciliary service is to help keep the elderly population out of institutions and in the community. By establishing purposeful but pleasureable exercise sessions in residential homes and day centres, it should be possible to maintain a degree of physical fitness and prevent deterioration. In the case of patients with deteriorating neurological conditions or general debility, the physiotherapist can advise the relatives on how to keep the patient at an optimum level. This would include teaching lifting and transferrals', and also assessing how much activity can be experted of the patient. Where a person who has had a cerebral vascular accident resulting in hemiplegia is being nursed at home after the initial stage, the physiotherapist can teach the patient and relatives suitable exercises which are regularly supervised and progressed.

Domiciliary physiotherapy can act as a follow up service for patients discharged from hospital who might otherwise need further treatment as outpatients. An example is provided by the discharge of numerous elderly women who have sustained fractured neck or femur, from the general hospital orthopaedic wards. These women are usually rehabilitated up to the stage of slow ambulation before discharge, but this does not adequately allow them to return to a normal existence. It is known that many spend their entire day either in a chair or in bed, especially if there is nobody to look after them. Physiotherapy here would serve to motivate the patient and prevent further deterioration. If it were known that there was going to be a physiotherapist supervising the case, then patients could be discharged earlier, with a resulting increase in the tumover of hospital beds.

Other practical considerations in the provision of a domiciliary service must include: provision of a comprehensive insurance policy for physiotherapists; transport arrangements (therapists could use personal vehicles and be reimbursed by the employing agency); equipment which needs to be of a light portable nature. Organisation of the service could be maintained through a central telephone service located in the hospital. For this purpose a secretary or clerk would need to be employed; after hours service could be provided by a Pageboytype communications system. Initial publicity of the service would need to be very intensive to make doctors aware of its possibilities. Finally it would be essential to keep good records of all patients. These must include initial assessment, treatment programme, progress and condition of the patient on discharge. Such records are vital because the doctor and physiotherapist may have even less time and face-to-face contact than in the hospital situation. They are also important because they provide essential data for the periodic re-evaluation of the service. Evaluative mechanisms such as statistical analysis and frequent multi-disciplinary discussions on the effectiveness of the programme must be built into the programme in the planning stage. The aid of statisticians and accountants may be employed and the programme should aim to produce figures on its efficiency within a specified period e.g. five years.

It is felt that a programme as described above would be a small beginning to the establishment of physiotherapy in our community. Once the benefits are seen, then the service could be expanded and modified as necessary.
The need for an expansion of physiotherapy has been recognised on an official level in South Africa. In the Government Gazette No. 4525 of the 29th November, 1974, the regulations defining the scope of the profession of physiotherapy are outlined. The fourteenth item is entitled Community Care, and it is said to incorporate "prophylactic physiotherapy services, district and domiciliary services, Day hospital organisations and rehabilitation centres including schools, industries and others".

This statutory recognition of Physiotherapy is very encouraging. The challenge remains now to put it into practice.

\section{References}

1. Bauer, D. (1975). 'Developing a role for a rural physiotherapist'. Physiotherapy, 61(4).

2. Carlyle-Goodge, P. (1974). 'Public Relations: Essential for awareness and support'. Physiotherapy 26(3).

3. Duncan, J. (1973). 'A three day course for district nurses on: Simple physiotherapy in the rehabilita tion of the housebound patient'. Physiotherapy

4. Glauber, K. (1975). 'Physiotherapy in the Community'. Unpublished thesis available in the University of Witwatersrand Medical Library.

5. Itoh, M. and Lee, M. (1969). 'i he future role of rehabilitation medicine in community health'. Medicine in community healtin'. Medical Clinics of North America, 53(3).

6. King, M. (1966). 'Medical care in developlng countries'.

7. Mathewson, M. (1974). 'The female physical therapist after marriage - is she wasted?' Physiotherany Canada, 26(5).

8. Morley, D. (1973). 'Paediatric priorities in the developing world'. pp. 341-396.

9. Scott, A. (1974). 'What direction Physical Therapy education?' Physiotherapy Canada, 26(3).

10. Sharman, E. (1972). 'The problems of a rehabilitation service'. Physictherapy 58(1).

\section{BOOK REVIEW}

Postural Variations in Childhood. Author Cecile Asher, M.D., M.R.C.P., D.C.H., B.Sc. Book supplied by Butterworth \& Co. (South Africa) (Pty.) Ltd., P.O. Box 792, Durban, 4000. Price R12,75. Post Graduate Paediatric Series, General Editor, John Apley. This well illustrated book investigates the postural changes which take place during infancy, childhood and adolescence. It is based on 6 monthly clinical examinations of over 200 children. A general review of postural development is given and the natural history of various conditions such as knock knee, vagus heel, metatarsus varus, tight hamstrings and round shoulders is described in relation to the relevant anatomy.

Emphasis is placed on natural postural variations which occur at different ages due to changing rates of epiphyseal growth, variations in body type and balance responses relative to height and build, to name but a few of the influence on posture discussed in this book.

It is a book which should interest every physiotherapist who works with children who have poor posture and postural abnormalities and it highlights the fact that many aspects are worthy of consideration before deciding that treatment is necessary.

Book reviewed by N. Lennard, B.Sc. Phys. (Wits). 